\title{
Experience with exercise right heart catheterization in the diagnosis of pulmonary hypertension: a retrospective study
}

Stephan Keusch ${ }^{1}$, Anina Bucher ${ }^{1}$, Séverine Müller-Mottet ${ }^{1}$, Elisabeth Hasler ${ }^{1}$, Marco Maggiorini ${ }^{2}$, Rudolf Speich ${ }^{2}$ and Silvia Ulrich ${ }^{1,3^{*}}$

\begin{abstract}
Background: Data on exercise pulmonary hemodynamics in healthy people and patients with pulmonary hypertension $(\mathrm{PH})$ are rare. We analyzed exercise right heart catheterization (RHC) data in a symptomatic collective referred with suspected PH to characterize the differential response by diagnostic groups, to correlate resting with exercise hemodynamics, and to evaluate safety.

Methods: This is a retrospective single-center study reviewing data from patients in whom an exercise RHC was performed between January 2006 and January 2013. Patients with follow-up RHC under PH -therapy were excluded.

Results: Data from 101 patients were analyzed, none of them had an adverse event. In 35\% we detected a resting $\mathrm{PH}$ (27.8\% precapillary, $6.9 \%$ postcapillary). Exercise PH (mean pulmonary arterial pressure (mPAP) $>30 \mathrm{mmHg}$ at exercise) was found in $38.6 \%$, whereas in $25.7 \% \mathrm{PH}$ was excluded. We found a remarkable number of exercise PH in scleroderma patients, the majority being postcapillary. 83\% of patients with mPAP-values between 20 and $24.9 \mathrm{mmHg}$ at rest had exercise $\mathrm{PH}$. Patients with resting PH had worse hemodynamics and were older compared with exercise PH ones.

Conclusion: In this real-life experience in symptomatic patients undergoing exercise $\mathrm{RHC}$ for suspected $\mathrm{PH}$, we found that exercise RHC is safe. The facts that the vast majority of patients with mPAP-values between 20 and $24.9 \mathrm{mmHg}$ at rest had exercise $\mathrm{PH}$ and the older age of patients with resting $\mathrm{PH}$ may indicate that exercise $\mathrm{PH}$ is a precursor of resting $\mathrm{PH}$. Whether earlier treatment start in patients with exercise PH would stabilize the disease should be addressed in future studies.
\end{abstract}

Keywords: Exercise, Pulmonary arterial hypertension, Pulmonary hypertension, Right heart catheterization

\section{Background}

Pulmonary hypertension $(\mathrm{PH})$ is defined as a mean pulmonary artery pressure (mPAP) $\geq 25 \mathrm{mmHg}$ during resting right heart catheterization (RHC) in supine position for at least 15 minutes [1]. PH may occur in association with various diseases, but also without any obvious reason (idiopathic). PH has been classified by the World Health Organization (WHO) in 5 classes, namely pulmonary arterial hypertension (class I), $\mathrm{PH}$ owing to left heart disease

\footnotetext{
* Correspondence: silvia.ulrich@usz.ch

${ }^{1}$ Clinic of Pulmonology, University Hospital of Zurich, 8091 Zurich Switzerland

${ }^{3}$ Zurich Center for Integrative Human Physiology, Zurich, Switzerland

Full list of author information is available at the end of the article
}

(class II), pulmonary hypertension due to lung diseases and/or hypoxia (class III), chronic thromboembolic PH (class IV) and $\mathrm{PH}$ with unclear multifactorial mechanisms (class V) [2]. PH can only be safely diagnosed invasively by right heart catheterization. Hereby, precapillary PH can be separated from pulmonary venous hypertension by measurement of the pulmonary artery wedge pressure (PAWP).

The cardinal symptom of patients suffering from all forms of $\mathrm{PH}$ is exertional dyspnea. This is the reason why the condition is often diagnosed late in its clinical course. Most patients feel well at rest, however, increasingly minor exercise poses a major problem to the affected. Until recently, PH was not only defined as $\mathrm{mPAP} \geq 25 \mathrm{mmHg}$ at rest, but also as $>30 \mathrm{mmHg}$ at exercise [3-5]. However, to 
date only few data supporting this definition is available, and the normal response to exercise of healthy subjects, especially of elderly, is not well known. Thus, the definition of exercise-induced $\mathrm{PH}$ was cancelled during the WHO meeting in Dana Point, 2009 and not re-introduced in Nice, 2013 [1].

At our PH center at the University Hospital of Zurich, measurement of pulmonary hemodynamics during exercise by RHC, using a cycle ergometer in supine position, is performed since 2005.

As data on exercise hemodynamics in healthy people is mostly available from relatively old studies and data on $\mathrm{PH}$-affected patients is rare [6,7], we aimed to retrospectively analyze all exercise RHC performed at our center in order to correlate resting with exercise hemodynamics, to characterize the differential response to exercise in the various $\mathrm{PH}$ classes, and to investigate the value of exercise $\mathrm{RHC}$ in the upmost mPAP range of normal (from 20 to $24.9 \mathrm{mmHg}$ ) formerly labelled as borderline $\mathrm{PH}$. A further aim was to look at the safety of exercise RHC procedure.

\section{Methods}

\section{Study design and study subjects}

This is a retrospective, observational study performed at our referral center for $\mathrm{PH}$. We reviewed all $\mathrm{RHC}$ data from January 2006 until January 2013. Eligible patients were all those in whom a $\mathrm{RHC}$ with additional recording of exercise hemodynamics was performed. From the total 117 eligible patients we excluded 16 patients because they were already taking $\mathrm{PH}$ specific medical therapy and the exercise RHC was performed in the follow up after establishing appropriate targeted therapy (Figure 1). All patients included in the study $(n=101)$ were referred with clinical suspicion of $\mathrm{PH}$, mostly because of exertional dyspnea or progressive diffusion limitation for carbon monoxide in scleroderma patients, and a diagnostic RHC at rest and during exercise was performed.

\section{Methods}

By reviewing the medical histories we collected the hemodynamic data and patients' characteristics (demographics, vital signs, $\mathrm{PH}$ class according to Dana Point classification scheme, 6 minute walk distance, and functional limitation [WHO/NYHA class]). In addition, we looked for possible adverse events during or shortly after the RHC procedure and gathered follow up data regarding survival by clinical medical records or contacts to the treating physicians. RHC was performed in supine position using a conventional pulmonary artery catheter and Edwards Vigilance Monitor for cardiac output measuring (continuous cardiac output thermodilution catheter). The usual invasively measured hemodynamic parameters were recorded. Baseline measurements were recorded after 15 minutes of rest and repeated 5 to 10 minutes later. For further calculations the mean of these resting values was taken. For the exercise testing we used a dynamic, symptom limited, step-wise incremental cycling exercise protocol in supine position. Patients were challenged by a cycle

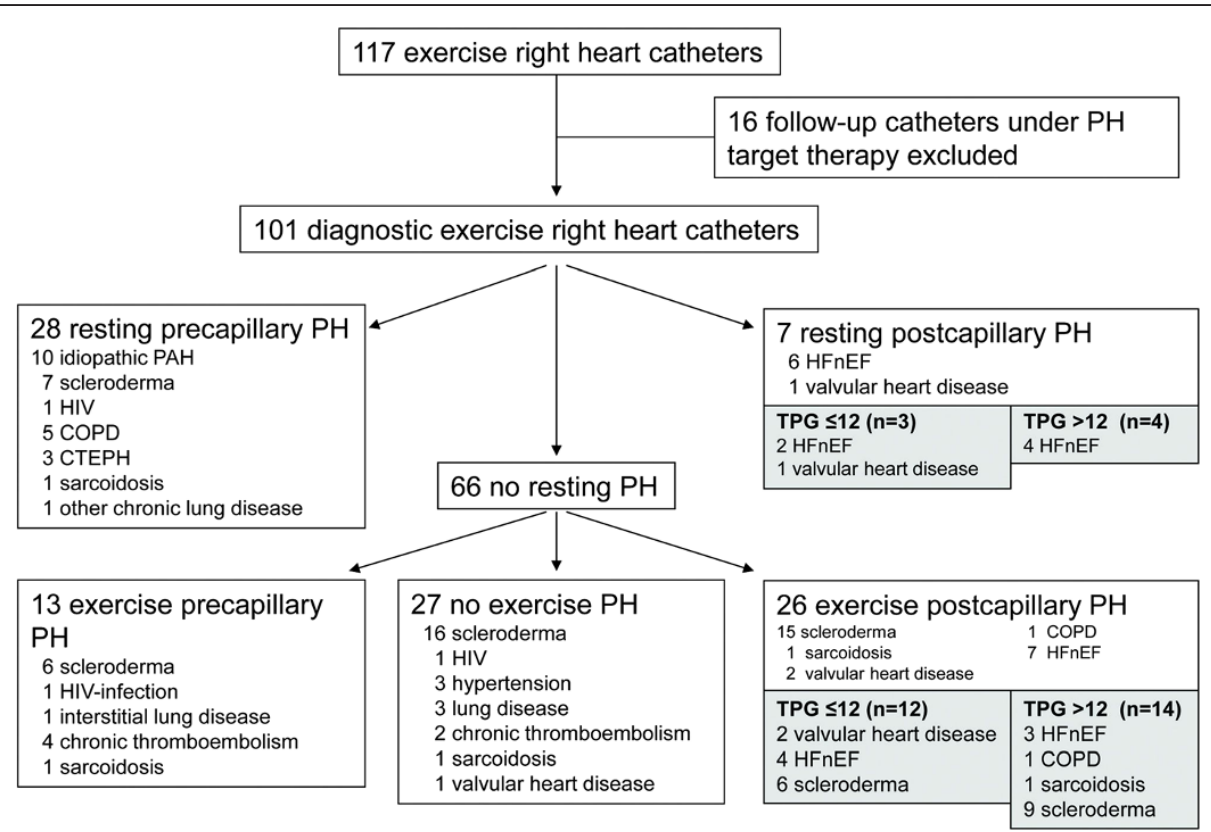

Figure 1 Patients and diagnostic groups after right heart catheterization. HFnEF, heart failure with normal ejection fraction, PAH, pulmonary arterial hypertension; $\mathrm{PH}$, pulmonary hypertension; COPD, chronic obstructive pulmonary disease; CTEPH, chronic thromboembolic pulmonary hypertension; TPG, transpulmonary pressure gradient. 
ergometry (TheraVital, Medica GMbH, Ravensburg) in supine position starting at 10 watts. The work load was increased every 3 minutes by 10 watts until symptoms occurred that lead to termination of exercise or in total 15 minutes of exercise was achieved. Data were recorded every 3 minutes before increasing the work load.

The patients were allocated to different diagnostic groups according to their resting hemodynamics and their hemodynamic response to exercise. The following groups were formed: (1) resting precapillary $\mathrm{PH}(\mathrm{mPAP} \geq$ $25 \mathrm{mmHg}$, PAWP < $15 \mathrm{mmHg}$; PAH group), (2) exercise precapillary $\mathrm{PH}$ (mPAP during exercise $>30 \mathrm{mmHg}$, PAWP < $15 \mathrm{mmHg}$; ePAH group), (3) resting postcapillary PH (mPAP $\geq 25 \mathrm{mmHg}$, PAWP >15 mmHg; PVH group), (4) exercise postcapillary PH (mPAP during exercise $>30$ $\mathrm{mmHg}$, PAWP > $15 \mathrm{mmHg}$; ePVH), (5) exercise out-ofproportion $\mathrm{PH}$ (mPAP during exercise $>30 \mathrm{mmHg}$, PAWP $>15 \mathrm{mmHg}$, transpulmonary gradient (TPG) > 12; eoPVH group) and (6) no $\mathrm{PH}$ (neither at rest, nor at exercise).

\section{Statistical analysis}

All baseline data are summarized by medians and quartiles. Baseline variables by groups were compared using Mann-Witney-U-Test. P $<0.05$ was considered significant. Statistica 10 (StatSoft, Inc., Tulsa, USA), SPSS 19 and Microsoft Excel (Version 2010) were used.

\section{Ethics}

All patients gave their written informed consent to register their data for scientific purposes and the study was approved by the local ethical authorities (KEK 20120125).

\section{Results}

A total of 101 patients with exercise performance during RHC were included. They all underwent catheterization because of clinical suspicion of $\mathrm{PH}$, mostly due to exertional dyspnea or progressive diffusion limitation for carbon monoxide in scleroderma patients. The overall baseline characteristics of these patients are shown in Table 1 and 2. According to the hemodynamic characteristics established during RHC the included patients were allocated to the different groups as described in the methods section. The absolute numbers in each group are listed in Figure 1. About one third of patients had resting $\mathrm{PH}$ (PAH or PVH). Out of the two thirds of patients without resting $\mathrm{PH} 13$ patients (20\%) suffered from ePAH, 26 had ePVH (39\%), and 27 patients (41\%) did not have elevated pulmonary pressures at rest or exercise. A high proportion of scleroderma $(\mathrm{n}=15,34 \%$ of all included scleroderma patients) were in the group of ePVH.

A separate clustering was done with patients that presented with mPAP from 20 to $24.9 \mathrm{mmHg}$. A total of 29
Table 1 Baseline characteristics

\begin{tabular}{ll}
\hline Total number of patients, $\mathrm{n}(\%)$ & 101 \\
Female, $\mathrm{n}(\%)$ & $70(69.3 \%)$ \\
Age, years & $61(52 ; 68)$
\end{tabular}

Relevant clinical diagnosis before Catheter-assessment, $\mathbf{n}(\%)$

$\begin{array}{ll}\text { Scleroderma } & 44(44 \%) \\ \text { Chronic lung disease } & 11(11 \%) \\ \text { History of pulmonary embolism } & 9(9 \%) \\ \text { Sarcoidosis } & 4(4 \%) \\ \text { HIV } & 3(3 \%) \\ \text { Other unclear dyspnea } & 30(30 \%)\end{array}$

NYHA/WHO functional class, $n(\%)$

Class 1/II

$11(11 \%) / 35(35 \%)$

Class III/IV

$42(41 \%) / 13(13 \%)$

Body mass index, $\mathrm{kg} / \mathrm{m} 2$

$25.1(21.9 ; 28.2)$

6 minute walking distance, $m$

$475(335 ; 539)$

Data given as median (quartiles) or number (\%). NYHA: New York Heart Association, WHO: World Health Organization.

patients fitted according to their hemodynamics in this group. A high proportion of these patients $(\mathrm{n}=24)$ showed an elevation of mPAP above $30 \mathrm{~mm} \mathrm{Hg}$ during exercise (83\%). Eight patients presented with ePAH (28\%) and 16 patients presented with ePVH (55\%), only 5 patients in this cluster had no $\mathrm{PH}$ at exercise (17\%).

A total of 37 patients had mPAP $<20 \mathrm{mmHg}$. Intriguingly 15 patients in this group presented with exercise $\mathrm{PH}$ forms (40.5\%); namely 5 with $\mathrm{ePAH}$, and 10 with ePVH.

Comparisons between the different $\mathrm{PH}$ groups showed mainly a greater variance in the pulmonary hemodynamics in the groups of resting $\mathrm{PH}$, either precapillary or postcapillary (see Table 3). In precapillary PH groups we found a greater increase in mPAP during exercise in $\mathrm{PAH}$ compared to the ePAH group. Accordingly, also right atrial pressure and pulmonary vascular resistance were higher, arterial oxygen saturation and mixed venous oxygen saturation were lower in the $\mathrm{PAH}$ group. The mean blood pressure at exercise was higher in the PVH group compared to non- $\mathrm{PH}$ patients. The increase in mPAP was statistically not different in the postcapillary $\mathrm{PH}$ groups (PVH versus ePVH). The right atrial pressure and per definition the PAWP were higher in PVH.

Comparison between ePVH and eoPVH was performed. The baseline characteristics did not show any statistical differences. The pulmonary hemodynamics were more compromised in the eoPVH group showing a higher MPAP and PVR at rest and a greater increase in PVR during exercise compared to $\mathrm{ePVH}$.

The median follow up for mortality in all patients was 1,024 days $(289 ; 1,287)$. The length of follow up of each group as well as deaths and adverse events are shown in 
Table 2 Patients characteristics according to diagnostic groups

\begin{tabular}{|c|c|c|c|c|c|c|}
\hline $\begin{array}{l}\text { Diagnostic } \\
\text { group }\end{array}$ & $\begin{array}{l}\text { Resting precapillary } \\
\text { PH, PAH }(n=28)\end{array}$ & $\begin{array}{l}\text { Exercise precapillary } \\
\text { PH, ePAH }(n=13)\end{array}$ & $\begin{array}{l}\text { Resting } \\
\text { postcapillary } \\
\mathrm{PH}, \mathrm{PVH}(n=7)\end{array}$ & $\begin{array}{l}\text { Exercise postcapillary } \\
\text { PH, ePVH }(n=12)\end{array}$ & $\begin{array}{l}\text { Exercise postcapillary } \\
\text { out-of-proportion } \\
\text { PH, eoPVH }(n=14)\end{array}$ & No $\mathrm{PH}(n=27)$ \\
\hline Age, years & $63.7^{\natural}(58.6 ; 70.4)$ & $53.9(51.8 ; 62.6)$ & $73.4^{\natural}(64.3 ; 73.8)$ & $61.2(51.0 ; 67.4)$ & $61.3(54.6 ; 68.3)$ & $53.9(43.3 ; 66.0)$ \\
\hline Females, $\mathrm{n}$ & $15(53.6)$ & $9(69.2)$ & $6(85.7)$ & $8(66.7)$ & $9(64.3)$ & $23(85.2)$ \\
\hline $\mathrm{BMI}, \mathrm{kg} / \mathrm{m} 2$ & $25.3^{\pi}(22.3 ; 27.8)$ & $25.9(23.2 ; 28.1)$ & $28.0^{\pi}(24.4 ; 30.2)$ & $25.1(21.8 ; 27.8)$ & $27.3^{n}(25.3 ; 29.7)$ & $22.8(18.7 ; 25.4)$ \\
\hline $\begin{array}{l}\text { NYHA class } \\
\| / I I / / \mathrm{V}, \mathrm{n}\end{array}$ & $28(100)$ & $12(92.3)$ & $7(100)$ & $10(83.3)$ & $12(85.7)$ & $21(77.8)$ \\
\hline $6 \mathrm{MWD}, \mathrm{m}$ & $459.5(296 ; 504)$ & $500(414 ; 552)$ & $437(339 ; 450)$ & $566(460 ; 603)$ & $490(330 ; 532)$ & $450(300 ; 540)$ \\
\hline $\begin{array}{l}\mathrm{SpO}_{2} \text { after } \\
\text { 6MWD, \% }\end{array}$ & $90(80 ; 93)$ & $93.5(82 ; 96)$ & $95(95 ; 96)$ & $96(94 ; 98)$ & $94(89 ; 96)$ & $94(89 ; 95)$ \\
\hline $\begin{array}{l}\text { HR after } \\
\text { 6MWD, bpm }\end{array}$ & $109(91 ; 127)$ & $104(83 ; 115)$ & $98(88 ; 109)$ & $104(91 ; 116)$ & $118(108 ; 137)$ & $103(100 ; 120)$ \\
\hline $\begin{array}{l}\text { SBP after } \\
\text { 6MWD, } \mathrm{mmHg}\end{array}$ & $138(120 ; 161)$ & $131(120 ; 142)$ & $175(154 ; 198)$ & $130(116 ; 154)$ & $155(140 ; 160)$ & $139(138 ; 158)$ \\
\hline
\end{tabular}

Data given as median (quartiles) or number (\%). $=\mathrm{p}<0.05$ compared to patients with no $\mathrm{PH}$. No significant differences between exercise postcapillary PH and exercise postcapillary out-of-proportion $\mathrm{PH}$ were detected.

6MWD, Six minute walk distance, BMI, Body mass index; ePAH, Exercise precapillary pulmonary hypertension; eoPVH, Exercise postcapillary out-of-proportion pulmonary hypertension; ePVH, Exercise postcapillary pulmonary hypertension; $H R$, Heart rate; $N Y H A$, New York Heart Association, $P A H$, Pulmonary arterial hypertension; $P H$,

Pulmonary hypertension; $\mathrm{PVH}$, Postcapillary pulmonary hypertension; $\mathrm{SpO}_{2}$, Peripheral oxygen saturation; SBP, Systemic blood pressure.

Table 4. The event rate and group size were too small to establish mortality differences between groups. During performance of RHC with exercise we encountered no adverse events and consider the procedure in experienced hands as safe.

\section{Discussion}

In this observational study of patients with clinical suspicion of $\mathrm{PH}$ we found resting $\mathrm{PH}$ in $35 \%$ of patients. In $38.6 \%$ of patients we detected either precapillary $(\mathrm{ePAH})$ or postcapillary exercise $\mathrm{PH}(\mathrm{ePVH})$ and in $25.7 \%$ of patients $\mathrm{PH}$ could be excluded. We found a remarkable number of exercise $\mathrm{PH}$ in the scleroderma patients (ePAH or ePVH), a population well-known for its highest risk of developing $\mathrm{PH}$. A great number of ePVH was found in this patient collective. In the cluster of patients with resting mPAP-values between 20 and $24.9 \mathrm{mmHg}, 83 \%$ showed exercise $\mathrm{PH}$. The groups of resting $\mathrm{PH}$ forms showed more severe hemodynamic compromise of the pulmonary vasculature.

The normal pressures in the pulmonary vascular bed at rest and mainly at exercise are still in discussion. In early studies of Wood in the 1950s a normal mPAP of $20 \mathrm{mmHg}$ was estimated $[7,8]$. Actual guidelines define $\mathrm{PH}$ by a cut-off-value of $\geq 25 \mathrm{mmHg}$, whereas a recent systematic review showed that the upper limit of normal is about 20 to $21 \mathrm{mmHg}$ [6]. During exercise the physiological rise in pulmonary pressures is intensively debated. Until the WHO consensus guidelines in 2009, it was accepted that a mPAP $>30 \mathrm{mmHg}$ during exercise exceeds the limits of normal [4]. Because of insufficient data on exercise pulmonary hemodynamics, this definition did not find its way in the latest guidelines [1]. A systematic review of historically reported exercise RHC in presumptively healthy people found an age-dependent rise in mPAP during exercise. $21 \%$ of healthy persons aged $<50$ years reached mPAP-values of $>30 \mathrm{mmHg}$ and $47 \%$ of subjects $>50$ years showed a mPAP of $>30$ $\mathrm{mmHg}$ at maximal exercise [6]. In our study of symptomatic patients with a median age of 61 years, including a high proportion of patients at highest risk for $\mathrm{PH}$ (scleroderma), nearly $40 \%$ of patients reached mPAPvalues above $30 \mathrm{mmHg}$ at relatively low exercise levels and we strongly believe that this increase was clinically relevant for the patients' symptoms. A remarkable large proportion of patients $(83 \%)$ with mPAP-values between 20 and $24.9 \mathrm{mmHg}$ are found in the exercise $\mathrm{PH}$ groups. This fact nourishes the suspicion that this group may suffer from early forms of $\mathrm{PH}$. A signal that even mPAP values $<20 \mathrm{mmHg}$ may already be associated with pathological exercise pulmonary hemodynamic derives from the fact that $40 \%$ of the symptomatic patients in our study with a $\mathrm{mPAP}<20 \mathrm{mmHg}$ reached values $>30 \mathrm{mmHg}$ during exercise. Also the significant rise of PVR during exercise in the ePAH group versus the no $\mathrm{PH}$ group indicates the pathological hemodynamic response of the pulmonary vascular bed during exercise in these patients. We found a significant correlation of the change in PVR with the six-minute walk distance $(\mathrm{r}=-0.271, \mathrm{p}=0.023$ and are thus in line with a meta-analysis by Savarese, who similarly showed a significant correlation of the change in PVR with exercise performance measured by the sixminute walking distance $(\mathrm{r}=-0.55, \mathrm{p}=0.04)$. No association with clinical events such as death or hospitalization could be established though [9]. In patients with chronic obstructive pulmonary disease or pulmonary 
Table 3 Hemodynamic data according to diagnostic groups

\begin{tabular}{|c|c|c|c|c|c|c|}
\hline Diagnostic group & $\begin{array}{l}\text { Resting } \\
\text { precapillary PH, } \\
\text { PAH }(n=28)\end{array}$ & $\begin{array}{l}\text { Exercise } \\
\text { precapillary PH, } \\
\text { ePAH }(n=13)\end{array}$ & $\begin{array}{l}\text { Resting } \\
\text { postcapillary PH, } \\
\text { PVH }(n=7)\end{array}$ & $\begin{array}{l}\text { Exercise } \\
\text { postcapillary PH, } \\
\text { ePVH }(n=12)\end{array}$ & $\begin{array}{l}\text { Exercise postcapillary } \\
\text { out-of-proportion } \\
\text { PH, eoPVH }(n=14)\end{array}$ & $\begin{array}{l}\text { No PH } \\
(n=27)\end{array}$ \\
\hline \multicolumn{7}{|l|}{ Resting hemodynamics } \\
\hline $\mathrm{HR}$, bpm & $79(69 ; 86.5)$ & $71.5(66 ; 83)$ & $79(74 ; 84)$ & $70.5^{\natural}(61 ; 74)$ & $76(70 ; 83)$ & $78(70 ; 86)$ \\
\hline Mean BP, mmHg & $91(85 ; 104)$ & $87(78 ; 91)$ & $110(78 ; 126)$ & $93(86 ; 101)$ & $95(84 ; 101)$ & $90(86 ; 104)$ \\
\hline Mean PAP, mmHg & $32^{9, *}(26 ; 44)$ & $20(18 ; 21)$ & $30^{9 ; *}(28 ; 34)$ & $19^{\S}(15 ; 22)$ & $22^{11}(19 ; 23)$ & $15(14 ; 18)$ \\
\hline Diastolic PAP, mmHg & $23^{\mathfrak{9}_{1} *}(18 ; 31)$ & $14^{\natural}(12 ; 15)$ & $21^{1 ; *}(19 ; 24)$ & $12(10 ; 15)$ & $15^{\natural}(13 ; 18)$ & $11(10 ; 14)$ \\
\hline RAP, $\mathrm{mmHg}$ & $8(4.5 ; 9.5)$ & $6(4 ; 7)$ & $9^{1, *}(7 ; 10)$ & $5(3 ; 8)$ & $6(4 ; 9)$ & $5(4 ; 7)$ \\
\hline PAWP, mmHg & $12^{9, *}(10 ; 13)$ & $8(8 ; 11)$ & $17^{1, *}(17 ; 19)$ & $12(8 ; 14)$ & $11^{\natural}(9 ; 12)$ & $8(7 ; 10)$ \\
\hline $\mathrm{TPG}, \mathrm{mmHg}$ & $23^{9, *}(17 ; 28)$ & $9^{n}(9 ; 12)$ & $13^{1, *}(11 ; 14)$ & $7^{\S}(5 ; 8)$ & $9^{\natural}(9 ; 12)$ & $7(6 ; 9)$ \\
\hline $\mathrm{DPG}, \mathrm{mmHg}$ & $10^{9 ; *}(8 ; 17)$ & $5^{\pi}(3 ; 7)$ & $4(1 ; 6)$ & $1^{1, \S}(0 ; 3)$ & $3(2 ; 6)$ & $2(1 ; 3)$ \\
\hline $\mathrm{Cl}, \mathrm{l} / \mathrm{min} / \mathrm{m}-2$ & $3.0(2.5 ; 3.5)$ & $3.4(2.8 ; 3.9)$ & $3.2(3.0 ; 4.8)$ & $3.0(2.75 ; 3.7)$ & $3.5(3.0 ; 4.0)$ & $3.0(2.7 ; 4.0)$ \\
\hline $\mathrm{CO}, \mathrm{I} / \mathrm{min}$ & $5.4(4.1 ; 6.7)$ & $6.3(4.9 ; 7.2)$ & $6.0(5.0 ; 10.8)$ & $5.3(4.6 ; 7.0)$ & $6.7^{\natural}(5.5 ; 7.4)$ & $5.1(4.2 ; 6.8)$ \\
\hline PVR, dynes***m-2 & $330^{1 ; *}(248 ; 415)$ & $135(112 ; 145)$ & $193(105 ; 247)$ & $83^{1,8}(63 ; 95)$ & $122(97 ; 175)$ & $109(90 ; 158)$ \\
\hline SVR, dynes* $s^{*} m-2$ & $1296(1018 ; 1656)$ & $1026(898 ; 1382)$ & $1031(717 ; 1875)$ & $1263(948 ; 1562)$ & $1196(1026 ; 1331)$ & $1340(1101 ; 1761)$ \\
\hline $\mathrm{SaO}_{2}, \%$ & $90.5^{9, *}(87.8 ; 93.9)$ & $95.0(93.0 ; 95.3)$ & $94.0(93.0 ; 95.0)$ & $94.8(92.7 ; 96.0)$ & $94.8(93.0 ; 95.3)$ & $94.8(93.0 ; 96.0)$ \\
\hline $\mathrm{PaO}_{2}, \mathrm{kPA}$ & $8.2^{1, * *}(7.6 ; 9.6)$ & $10.6(9.2 ; 11.7)$ & $9.5^{\natural}(8.9 ; 10.00)$ & $10.2(9.0 ; 11.7)$ & $10.3(9.4 ; 11.4)$ & $11.4(10.1 ; 12.2)$ \\
\hline $\mathrm{PaCO}_{2}, \mathrm{kPA}$ & $4.60(4.32 ; 5.35)$ & $4.65^{\natural}(4.51 ; 4.80)$ & $4.70(4.49 ; 5.30)$ & $4.85(4.50 ; 5.27)$ & $5.13(4.60 ; 5.30)$ & $5.05(4.75 ; 5.40)$ \\
\hline $\mathrm{SmvO}_{2}, \%$ & $66.1^{1 ; * *}(60.6 ; 70.5)$ & $71.0(69.0 ; 74.4)$ & $70.0(65.0 ; 71.0)$ & $71.6(68.4 ; 76.1)$ & $71.4(69.1 ; 73.5)$ & $70.0(65.4 ; 72.8)$ \\
\hline \multicolumn{7}{|c|}{ Hemodynamics during supine maximal cycling exercise } \\
\hline Watt achieved & $30(20 ; 50)$ & $30(20 ; 40)$ & $30(20 ; 30)$ & $30(20 ; 50)$ & $30(20 ; 45)$ & $30(20 ; 40)$ \\
\hline $\mathrm{HR}, \mathrm{bpm}$ & $110(103 ; 123)$ & $102(98 ; 116)$ & $111(101 ; 118)$ & $105(98 ; 122)$ & $116.5(106 ; 122)$ & $120(101 ; 126)$ \\
\hline Mean BP, mmHg & $115(101 ; 125)$ & $107(92 ; 114)$ & $128^{\natural}(102 ; 158)$ & $107(93 ; 120)$ & $107(103 ; 115)$ & $101(91 ; 113)$ \\
\hline Mean PAP, mmHg & $58^{\mathfrak{1}_{1 * *}}(50 ; 66)$ & $35^{\natural}(32 ; 37)$ & $47^{1, *}(42 ; 65)$ & $36^{n}(31 ; 41)$ & $42^{n}(38 ; 43)$ & $24(18 ; 27)$ \\
\hline $\begin{array}{l}\text { Increase in mPAP with } \\
\text { exercise, } \mathrm{mmHg}\end{array}$ & $20^{9, *}(16 ; 30)$ & $14^{\natural}(13 ; 19)$ & $17^{\natural}(12 ; 31)$ & $16^{\pi}(12 ; 25)$ & $19^{9}(14.7 ; 21)$ & $7(3 ; 9)$ \\
\hline $\begin{array}{l}\text { Increase in mPAP } \\
\text { per Watt, mmHg }\end{array}$ & $0.73^{9}(0.53 ; 1.05)$ & $0.47^{\natural}(0.33 ; 0.74)$ & $0.57^{\natural}(0.40 ; 1.10)$ & $0.48^{\natural}(0.36 ; 0.77)$ & $0.66^{n}(0.35 ; 0.85)$ & $0.20(0.10 ; 0.33)$ \\
\hline Diastolic PAP, mmHg & $40^{\boldsymbol{1}_{1 *}}(32 ; 45)$ & $24^{\pi}(22 ; 25)$ & $30(26 ; 40)$ & $27^{\natural}(24 ; 30)$ & $30(25 ; 31)$ & $16(12 ; 18)$ \\
\hline RAP, $\mathrm{mmHg}$ & $12^{9, *}(7 ; 17)$ & $7(3 ; 8)$ & $16^{9, *}(9 ; 18)$ & $10^{n}(7 ; 11)$ & $8^{n}(6 ; 9)$ & $5(2 ; 7)$ \\
\hline PAWP, mmHg & $16^{1, *}(13 ; 21)$ & $12(10 ; 14)$ & $32^{1, *}(27 ; 36)$ & $26.5^{\natural}(23 ; 34)$ & $21.5^{\pi}(17 ; 28)$ & $10(7 ; 15)$ \\
\hline $\mathrm{TPG}, \mathrm{mmHg}$ & $41^{1, *}(34 ; 45)$ & $22^{\natural}(21 ; 29)$ & $16(8 ; 30)$ & $9^{9,5}(6 ; 12)$ & $18^{\natural}(16 ; 21)$ & $12(9 ; 14)$ \\
\hline $\mathrm{DPG}, \mathrm{mmHg}$ & $21^{1, *}(13 ; 29)$ & $11^{\natural}(10 ; 13)$ & $1(-9 ; 7)$ & $-1.5^{\natural, \S}(-6.5 ; 2.0)$ & $5.5(3 ; 9)$ & $4(2 ; 6)$ \\
\hline $\mathrm{Cl}, \mathrm{l} / \mathrm{min} / \mathrm{m}-2$ & $3.8(3.0 ; 4.3)$ & $4.0(3.7 ; 4.7)$ & $3.7(3.3 ; 5.4)$ & $3.7(3.2 ; 4.1)$ & $4.2(3 ; 4.8)$ & $3.8(3.1 ; 4.3)$ \\
\hline $\mathrm{CO}, \mathrm{I} / \mathrm{min}$ & $6.8(5.0 ; 8.3)$ & $7.2(6.7 ; 8.4)$ & $6.5(5.6 ; 12.1)$ & $6.5(5.5 ; 8.0)$ & $7.06(6.44 ; 8.83)$ & $6.4(4.8 ; 8.3)$ \\
\hline PVR, dynes*** $s^{*} m-2$ & $487^{1 / *}(398 ; 534)$ & $251^{\natural}(207 ; 335)$ & $163(100 ; 198)$ & $97^{1,8}(82 ; 119)$ & $173.5(148 ; 227)$ & $139(107 ; 229)$ \\
\hline Delta PVR, dynes*s*m-2 & $126^{\natural}(68 ; 208)$ & $103^{9}(73 ; 167)$ & $15(-89 ; 93)$ & $16^{1,8}(-9 ; 36)$ & $57(37 ; 97)$ & $34(11 ; 89)$ \\
\hline SVR, dynes* $s^{*} m-2$ & $1186(866 ; 1679)$ & $1031(907 ; 1077)$ & $1413(739 ; 1541)$ & $1164(903 ; 1327)$ & $989.5(911 ; 1251)$ & $1222(933 ; 1755)$ \\
\hline $\mathrm{SaO}_{2}, \%$ & $88.0^{\boldsymbol{1}_{1 * *}}(80.0 ; 94.0)$ & $95.0(86.0 ; 96.0)$ & $96.0(94.0 ; 97.0)$ & $94(93 ; 95)$ & $93.4^{\natural}(91 ; 94.5)$ & $96.0(95.0 ; 97.0)$ \\
\hline $\mathrm{SmvO}_{2}, \%$ & $36.5^{\mathfrak{9}, *}(28.2 ; 43.5)$ & $52.0(38.0 ; 55.0)$ & $45.0(24.0 ; 50.0)$ & $44.5(33.5 ; 57.5)$ & $50(36 ; 58)$ & $48.0(40.0 ; 55.0)$ \\
\hline
\end{tabular}

Data given as median (quartiles) or number (\%). ${ }^{n}=\mathrm{p}<.05$ compared to patients with no $\mathrm{PH} .{ }^{*}=\mathrm{p}<.05$ compared to patients with appropriate exercise $\mathrm{PH}$ (either resting precapillary $\mathrm{PH}$ compared to exercise precapillary $\mathrm{PH}$, or resting postcapillary $\mathrm{PH}$ compared to exercise postcapillary $\mathrm{PH}$ ). ${ }^{\S}=\mathrm{p}<.05$ compared to exercise out-of-proportion $\mathrm{PH}$.

$\mathrm{BP}$, Blood pressure; $\mathrm{Cl}$, Cardiac index; $\mathrm{CO}$, Cardiac output; DPG, Diastolic pressure gradient; ePAH, Exercise precapillary pulmonary hypertension; eoPVH, Exercise

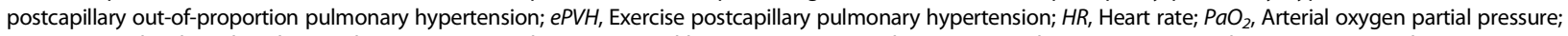
$\mathrm{PaCO}_{2}$, Arterial carbon dioxide partial pressure; $P A H$, Pulmonary arterial hypertension; $P A P$, Pulmonary arterial pressure; $P A W P$, Pulmonary artery wedge pressure; $P H$, Pulmonary hypertension; $P V H$, Postcapillary pulmonary hypertension; $P V R$, Pulmonary vascular resistance; $R A P$, Right atrial pressure; $S a O_{2}$, Arterial oxygen saturation; $\mathrm{SmVO}_{2}$, Mixed venous oxygen saturation; SVR, Systemic vascular resistance; TPG, Transpulmonary pressure gradient. 
Table 4 Follow up, adverse events and mortality data

\begin{tabular}{|c|c|c|c|c|c|c|}
\hline Diagnostic group & $\begin{array}{l}\text { Resting } \\
\text { precapillary } \\
\mathrm{PH}(\mathrm{n}=28)\end{array}$ & $\begin{array}{l}\text { Exercise } \\
\text { precapillary } \\
\mathrm{PH}(n=13)\end{array}$ & $\begin{array}{l}\text { Resting } \\
\text { postcapillary } \\
\mathrm{PH}(\mathrm{n}=7)\end{array}$ & $\begin{array}{l}\text { Exercise } \\
\text { postcapillary } \\
\mathrm{PH}(n=12)\end{array}$ & $\begin{array}{l}\text { Exercise postcapillary } \\
\text { out-of-proportion } \\
\text { PH }(n=14)\end{array}$ & $\begin{array}{l}\text { No PH } \\
(n=27)\end{array}$ \\
\hline Follow-up days, $\mathrm{n}$ & $1,080(246 ; 1231)$ & $1,031(366 ; 1346)$ & $1,080(279 ; 1290)$ & $718(321 ; 1440)$ & $1,112(542 ; 1332)$ & $714(282 ; 1241)$ \\
\hline Death, $\mathrm{n}$ & 1 & 1 & 1 & 1 & 0 & 2 \\
\hline Lung transplantation, $\mathrm{n}$ & 3 & 0 & 0 & 0 & 0 & 0 \\
\hline Pulmonary endarterectomy, $\mathrm{n}$ & 2 & 1 & 0 & 0 & 0 & 0 \\
\hline Adverse events at $\mathrm{RHC}, \mathrm{n}$ & 0 & 0 & 0 & 0 & 0 & 0 \\
\hline
\end{tabular}

A low event rate precludes statistical comparison. $\mathrm{PH}$, Pulmonary hypertension, $\mathrm{RHC}$, Right heart catheterization.

fibrosis resting mPAP values of > 17-18 $\mathrm{mmHg}$ were already associated with increased mortality or clinical worsening $[10,11]$.

The impact of age and its physiological effect on exercise pulmonary hemodynamics is difficult to establish in lack of data in healthy and diseased subjects. Recently, Whyte published data on 38 patients aged $<50$ years and free of $\mathrm{PH}$ who underwent resting and exercise RHC. Out of these 38 patients, 63\% developed mPAPvalues $>30 \mathrm{mmHg}$ at mild-to-moderate exercise $(<60$ Watt). Compared to healthy subjects not increasing their mPAP above $30 \mathrm{mmHg}$, those with a significant increase in mPAP showed higher resting mPAP and higher PVR [12]. In another study of symptomatic patients referred for RHC, a greater number showed PVH (48\%). From those classified as PAH 84\% suffered from ePAH. The mean age of this group was 58.8 years [13]. In a registry analysis of Condliffe in connective tissue disease-associated PAH the proportion of patients with ePAH was $11.4 \%$ and about $19 \%$ of them progressed within 2 to 3 years to PAH. Progression to PAH in this scleroderma cohort occurred in $60 \%$ of patients with ePAH who died in the follow up period of maximal 6 years [14]. We believe that further studies have to shed light on this issue, especially on the age-dependency of cut-off values during exercise.

In our scleroderma subgroup, a collective that is at highest risk for developing $\mathrm{PH}$, we found pre- and postcapillary $\mathrm{PH}$-forms. A high number suffered from ePVH without signs of disturbances in the pulmonary vascular bed (not out-of-proportion). A similarly high proportion of ePVH was found in a scleroderma collective by Saggard with $21 \%$ of patients $(n=54$, resting $\mathrm{PH}$ was excluded) [15]. This underlines the need to collect more information on exercise pulmonary hemodynamics during $\mathrm{RHC}$, as echocardiography would probably misclassify some patients since no PAWP can accurately be determined. None of the 44 scleroderma patients in this collective had postcapillary $\mathrm{PH}$ at rest, but a remarkable $1 / 3$ had ePVH. This might explain why these patients were symptomatic with dyspnea and thus scheduled for RHC. However, the course of this entity and the best treatment options need to be better defined. Further observational and treatment studies will show if the classification by exercise hemodynamics is able to separate patients according to treatment response and outcome.

Our report on exercise $\mathrm{RHC}$ in real life illustrates the difficulties of daily clinical practice to classify patients. Too little is known about the exercise $\mathrm{PH}$ forms and their clinical course or benefit of treatment with PAHspecific therapy. Can an elevated mPAP> $30 \mathrm{mmHg}$ at maximal exercise of $20 \mathrm{Watt}$ in a symptomatic patient with scleroderma be compared to a similar absolute mPAP increase in a healthy patient at 150 Watt? In our and others opinion the answer would be no [7]. Should we treat ePAH or wait until PAH will develop years later? What does postcapillary out-of-proportion $\mathrm{PH}$ during exercise signify? Our real-life data show that the classification of patients with exertional dyspnea into $\mathrm{PH}$ classes or subcategories of formerly labelled borderline $\mathrm{PH}$ or exercise $\mathrm{PH}$ is difficult and more a continuum than clearly distinguished groups. We hope that with future prospective studies more insight can be gathered to this clinically important issue.

Performing maximal symptom-limited exercise RHC in sometimes highly symptomatic $\mathrm{PH}$ patients was absolutely safe in our collective, as we did not encounter any adverse events. As others, we believe that in experienced hands this diagnostic tool is safe and can be performed in clinical routine in the diagnostic work-up of patients with suspicion of $\mathrm{PH}[16,17]$. However, a problem in clinical practice and research is that no standardized protocols for exercise RHC testing are available. Important issues in performing exercise $\mathrm{RHC}$ are the type of exercise (dynamic vs. static), the increase in work load (linear, step-wise) and the body position during exercise. We used a completely supine position with a bicycle fixed at the end of the patient bed. In this position, subjects will perform considerably less work load compared to up-right cycling. However, the supine position has the advantage of a similar and calm thorax position for measurements. In general, it is accepted that exercise should rather be dynamic to avoid increases in systemic resistance and that intrathoracic pressure swings should be carefully reduced due to their effects on the pressure 
transducers in the pulmonary vasculature [18]. Therefore, isotonic arm exercise as it is performed in some catheter laboratories, should be discouraged [19].

Limitations of our study are, apart from the singlecenter experience and the retrospective design, the rather small number of patients in the different groups and the relatively short follow up with very few events, which did not allow estimates on prognosis. The patients in our collective where slightly overweight (mean BMI $25.1 \mathrm{~kg} / \mathrm{m}^{2}$ ), which corresponds to the Swiss general population and other $\mathrm{PH}$-collectives published. Intrinsically to the trial design, we do not have a healthy matched control group and we were thus limited to compare symptomatic patients according to their hemodynamic profile. Therefore, insight in normal physiological response is limited.

\section{Conclusion}

In this real-life experience in symptomatic patients undergoing exercise $\mathrm{RHC}$ for suspected $\mathrm{PH}$, we found that exercise RHC is safe without any adverse events. Patients with diseases known to be associated with $\mathrm{PH}$, such as scleroderma, were found in all hemodynamically defined groups, and this underscores the importance of RHC in the diagnosis of $\mathrm{PH}$. The facts that the vast majority of patients with mPAP-values between 20 and $24.9 \mathrm{mmHg}$ at rest develop exercise $\mathrm{PH}$ and that patients with resting $\mathrm{PH}$ are older strongly argue for exercise $\mathrm{PH}$ as a precursor of resting $\mathrm{PH}$. Whether an earlier treatment start in patients with exercise $\mathrm{PH}$ (especially ePAH) would stabilize the disease should be addressed in future studies.

\section{Abbreviations \\ DPG: Diastolic pulmonary gradient (diastolic PAP - PAWP); ePAH: Exercise precapillary pulmonary hypertension; eoPVH: Exercise postcapillary out-of- proportion pulmonary hypertension; ePVH: Exercise postcapillary pulmonary hypertension; mPAP: Mean pulmonary artery pressure; NYHA: New York Heart Association; PAH: Pulmonary arterial hypertension; PVH: Postcapillary pulmonary hypertension; PAWP: Pulmonary artery wedge pressure; PH: Pulmonary hypertension; RHC: Right heart catheterization; TPG: Transpulmonary gradient (mPAP - PAWP); WHO: World Health Organization.}

\section{Competing interests}

The authors declare that they have no competing interests.

\section{Authors' contributions}

All authors read and approved the final manuscript.

\section{Acknowledgements}

We thank the Swiss national Science Foundation and the Zurich Lung League for financial support.

\section{Funding}

Swiss National Science Foundation and Zurich Lung League.

\section{Author details}

${ }^{1}$ Clinic of Pulmonology, University Hospital of Zurich, 8091 Zurich, Switzerland. ${ }^{2}$ Clinic for Internal Medicine, University Hospital of Zurich, Zurich, Switzerland. ${ }^{3}$ Zurich Center for Integrative Human Physiology, Zurich, Switzerland.

Received: 29 June 2014 Accepted: 1 September 2014 Published: 15 October 2014

\section{References}

1. Simonneau G, Gatzoulis MA, Adatia I, Celermajer D, Denton C, Ghofrani A, Gomez Sanchez MA, Krishna Kumar R, Landzberg M, Machado RF, Olschewski H, Robbins IM, Souza R: Updated clinical classification of pulmonary hypertension. J Am Coll Cardiol 2013, 62(25 Suppl):D34-D41.

2. Hoeper MM, Bogaard HJ, Condliffe R, Frantz R, Khanna D, Kurzyna M, Langleben D, Manes A, Satoh T, Torres F, Wilkins MR, Badesch DB: Definitions and diagnosis of pulmonary hypertension. J Am Coll Cardiol 2013, 62 (25 Suppl):D42-D50.

3. Barst RJ, McGoon M, Torbicki A, Sitbon O, Krowka MJ, Olschewski H, Gaine S: Diagnosis and differential assessment of pulmonary arterial hypertension. J Am Coll Cardiol 2004, 43:40S-47S.

4. Simonneau G, Galie N, Rubin LJ, Langleben D, Seeger W, Domenighetti G, Gibbs S, Lebrec D, Speich R, Beghetti M, Rich S, Fishman A: Clinical classification of pulmonary hypertension. J Am Coll Cardiol 2004, 43(12 Suppl S):5S-12S.

5. Chemla D, Castelain V, Herve P, Lecarpentier Y, Brimioulle S: Haemodynamic evaluation of pulmonary hypertension. Eur Respir J 2002, 20:1314-1331.

6. Kovacs G, Berghold A, Scheidl S, Olschewski H: Pulmonary arterial pressure during rest and exercise in healthy subjects: a systematic review. Eur Respir J 2009, 34:888-894.

7. Naeije R, Vanderpool R, Dhakal BP, Saggar R, Vachiery UL, Lewis GD: Exercise-induced pulmonary hypertension: physiological basis and methodological concerns. Am J Respir Crit Care Med 2013, 187:576-583.

8. Wood P: Pulmonary hypertension with special reference to the vasoconstrictive factor. Br Heart J 1958, 20:557-570.

9. Savarese G, Musella F, D'Amore C, Losco T, Marciano C, Gargiulo P, Rengo G, Dellegrottaglie S, Bossone E, Leosco D, Perrone-Filardi P: Hemodynamics, exercise capacity and clinical events in pulmonary arterial hypertension. Eur Respir J 2013, 42:414-424.

10. Hamada K, Nagai S, Tanaka S, Handa T, Shigematsu M, Nagao T, Mishima M, Kitaichi M, Izumi T: Significance of pulmonary arterial pressure and diffusion capacity of the lung as prognosticator in patients with idiopathic pulmonary fibrosis. Chest 2007, 131:650-656.

11. Kessler R, Faller M, Fourgaut G, Mennecier B, Weitzenblum E: Predictive factors of hospitalization for acute exacerbation in a series of 64 patients with chronic obstructive pulmonary disease. Am J Respir Crit Care Med 1999, 159:158-164

12. Whyte $K$, Hoette S, Herve $P$, Montani $D$, Jais $X$, Parent F, Savale L, Natali D, O'Callaghan DS, Garcia G, Sitbon O, Simonneau G, Humbert M, Chemla D: The association between resting and mild-to-moderate exercise pulmonary artery pressure. Eur Respir J 2012, 39:313-318.

13. Tolle JJ, Waxman AB, Van Horn TL, Pappagianopoulos PP, Systrom DM: Exercise-induced pulmonary arterial hypertension. Circulation 2008, 118:2183-2189.

14. Condliffe R, Kiely DG, Peacock AJ, Corris PA, Gibbs JS, Vrapi F, Das C, Elliot CA, Johnson M, DeSoyza J, Torpy C, Goldsmith K, Hodgkins D, Hughes RJ, Pepke-Zaba J, Coghlan JG: Connective tissue disease-associated pulmonary arterial hypertension in the modern treatment era. Am J Respir Crit Care Med 2009, 179:151-157.

15. Saggar R, Khanna D, Furst DE, Shapiro S, Maranian P, Belperio JA, Chauhan N, Clements P, Gorn A, Weigt SS, Ross D, Lynch JP 3rd, Saggar R: Exercise-induced pulmonary hypertension associated with systemic sclerosis: four distinct entities. Arthritis Rheum 2010, 62:3741-3750

16. Fowler RM, Maiorana AJ, Jenkins SC, Gain KR, O'Driscoll G, Gabbay E: Implications of exercise-induced pulmonary arterial hypertension Med Sci Sports Exerc 2011, 43:983-989.

17. Sun $X G$, Hansen JE, Oudiz RJ, Wasserman K: Exercise pathophysiology in patients with primary pulmonary hypertension. Circulation 2001, 104:429-435.

18. Saggar R, Sitbon O: Hemodynamics in pulmonary arterial hypertension: current and future perspectives. Am J Cardiol 2012, 110:9S-15S.

19. Hager WD, Collins I, Tate JP, Azrin M, Foley R, Lakshminarayanan S, Rothfield $\mathrm{NF}$ : Exercise during cardiac catheterization distinguishes between pulmonary and left ventricular causes of dyspnea in systemic sclerosis patients. Clin Respir J 2013, 7:227-236.

doi:10.1186/2049-6958-9-51

Cite this article as: Keusch et al.: Experience with exercise right heart catheterization in the diagnosis of pulmonary hypertension: a retrospective study. Multidisciplinary Respiratory Medicine 2014 9.51. 